\title{
BERDUSTA NAMUN DIPAKAI TUHAN DALAM 1 RAJA-RAJA 13
}

\author{
Rendy Tirtanadi \\ GKRI Jemaat Kelapa Gading \\ Korespondensi: rendy_tirta@yahoo.com
}

\begin{abstract}
ABSTRAK: Peranan nabi dalam kitab Perjanjian Lama merupakan pelayanan yang signifikan, karena nabi dipandang sebagai pengantara untuk bertindak atas nama Allah sendiri. Namun jika seorang nabi yang dipakai TUHAN itu berdusta, apakah ia masih layak untuk dipakai untuk menggenapi perintah/ firman-Nya? Dengan menelusuri narasi kitab 1 Raja-raja 13 perihal seorang nabi tua yang berdusta kepada abdi Allah yang dipakai TUHAN untuk menyatakan hukuman-Nya kepada raja Yeroboam, setiap orang Kristen khususnya para pelayan TUHAN dapat membedakan bahwa dipakai dan diperkenan oleh Allah merupakan dua hal yang berbeda.
\end{abstract}

KATA KUNCI: abdi Allah; nabi; perintah Allah; dusta.

ABSTRACT: The role of a prophet in the Old Testament has a significant ministry, because a prophet is viewed as a mediator between God and human, and act on behalf of God Himself. Nevertheless if a prophet who is used by God is lying, is he still worthy to be used to fulfill God's Word? By exploring the narration in 1 Kings 13 about the old prophet lying to a man of God who deliver the punishment message to Jeroboam, every Christian, especially God's servants can learn a lesson and discern the difference between being used and to be accepted by God.

KEYWORDS: A man of God; prophet; the word of the LORD; lying.

\section{Pendahuluan}

Perihal berdusta adalah suatu dosa yang sering diungkapkan di dalam kitab Perjanjian Lama, misalnya: dalam Yeremia 28:1-17 akan dusta 
Hananya yang menubuatkan perihal kembalinya raja Yehuda dan segala perkakas rumah TUHAN dari pembuangan di Babel dalam dua tahun; juga dalam Kejadian 27 dimana Yakub mengelabui ayahnya demi mendapatkan hak kesulungan. Pada kasus Yakub, nampaknya dustanya berhasil, namun ia tetap harus menanggung akibat dari dustanya itu.

Di dalam 1 Raja-raja 13, terdapat narasi tentang dusta dimana yang berdusta adalah seorang nabi, namun Firman TUHAN yang dinyatakan melalui nabi yang berdusta itu tetap terlaksana. Tema "berdusta namun dipakai Allah" sangat relevan dalam situasi kontemporer yang patut digumuli: bolehkah seorang percaya berdusta? Tulisan ini akan mempelajari konteks narasi 1 Raja-raja 13 dengan menelusuri latar belakang sejarah, budaya, dan gramatikal. Allah adalah suci, lantas bagaimana kita menjelaskan narasi ini dimana seorang nabi tua yang berdusta namun tetap dipakai Tuhan, sementara seorang abdi Allah yang diutus TUHAN untuk menyampaikan kebenaran Firman TUHAN dengan disertai tanda-tanda ajaib justru mendapatkan hukuman TUHAN.

Dalam konteks zaman sekarang ini, mayoritas berpendapat bahwa berdusta diperbolehkan bila mempunyai motivasi yang baik, sementara yang lain berpendapat bahwa semua dusta adalah dosa sehingga tidak dapat dibenarkan dengan alasan apapun. Bagaimana kita menanggapi "hamba-hamba Tuhan" tertentu yang mungkin saja berdusta, namun memiliki ribuan anggota jemaat di gereja yang dipimpinnya? ${ }^{1}$

\section{Latar Belakang Konteks Sosial-Religius}

Norman L. Geisler mengatakan bahwa,

dua tema yang mewarnai seluruh narasi dalam kitab Raja-raja: moralitas dari para raja yang memerintah dan pelayanan dari para nabi. Raja-raja

\footnotetext{
1 Lihat uraian Michael Horton, Kekristenan Tanpa Kristus, terj. Grace Purnamasari (Surabaya: Momentum, 2009), 61-65. https://www.britannica.com/biography/Jim-Jones (diakses tanggal 20 Juli 2018), Jim Jones yang mengaku "nabi" telah membawa tragedi kemanusiaan sekaligus mengisi lembaran sejarah kelam kekristenan dengan melakukan bunuh diri massal bersama lebih dari 900 orang lain di Guyana, Amerika Selatan.
} 
dari Israel Utara (Israel) semuanya jahat. Sementara itu di Kerajaan Selatan (Yehuda) ada pengecualian, karena adanya pembaruan yang dipengaruhi oleh pelayanan dari beberapa nabi. ${ }^{2}$

Ketika Tuhan menghukum raja Salomo karena ketidaksetiaannya untuk beribadah dan menyembah Allah Daud ayahnya, maka kerajaan Israel terpecah menjadi dua: Kerajaan Utara yang dipimpin oleh raja Yerobeam dan Kerajaan Selatan yang dipimpin oleh raja Rehabeam. Untuk mengambil hati rakyatnya agar tidak kembali beribadah ke Yerusalem sebagai pusat penyembahan kepada Tuhan pada waktu itu, maka Yerobeam membuat agama buatannya sendiri.

Beberapa pertimbangan raja Yerobeam seperti yang diuraikan oleh Matthew Henry adalah: ${ }^{3}$ pertama, raja Yerobeam memahami bila orang Israel kembali kepada agamanya yang lama, maka mereka akan kembali kepada rajanya yang lama (raja Rehabeam); kedua, raja Yerobeam pun berusaha mencegah orang Israel untuk kembali ke Yerusalem dengan menawarkan suatu kemudahan untuk pergi beribadah, dengan mengatakan: "Sudah cukup lamanya kamu pergi ke Yerusalem..." 4 ; ketiga, raja Yerobeam juga membuat dua anak lembu emas, yang melambangkan kehadiran Allah Israel. Kemungkinan besar Yerobeam mengadopsi cara penyembahan kepada allah Apis, ${ }^{5}$ yang ia peroleh saat dalam pelariannya ke Mesir. Ia tidak bermaksud melakukan praktek penyembahan berhala seperti kepada dewa Molokh atau Kamos, namun lebih kepada Allah Israel yang direpresentasikan dalam wujud lembu jantan (1 Raja-raja 12:28). Menurut Andrew E. Hill dan John H. Walton, Apis sebagai dewa lembu jantan juga merupakan penjelmaan putra

\footnotetext{
2 Norman L. Geisler, A Popular Survey of The Old Testament (Grand Rapids, Baker Academic, 1977), 129-130.

3 Matthew Henry, The Bethany Paralel Commentary (Minneapolis: Bethany House, 1985), 654 .

4 Kel. 12:28b.

5 Lihat https://www.britannica.com/topic/Apis-Egyptian-deity_(diakses tanggal 9 Juli 2018). Dijelaskan di sini bahwa Apis dalam Bahasa Yunani berarti lembu yang sakral dan bersifat ilahi di sembah di Memphis, Mesir. Pada awalnya kemunculan Apis mungkin dikaitkan dengan dewa kesuburan yang berkaitan dengan daya produksi gandum dan ternak.
} 
Osiris. ${ }^{6}$ John Gill berbeda pendapat dengan Henry, maupun Hill dan Walton. Gill mengatakan bahwa Yerobeam membuat dua patung karena dua alasan. Pertama karena meniru model dan kesuksesan dari anak lembu emas buatan Harun (Keluaran 32). Kedua mengambil pola penyembahan lembu yang berjumlah dua: satu di Memphis yang disebut Apis dan yang lainnya dinamakan Mnevis yang disembah di Hierapolis. ${ }^{7}$ Penulis berpendapat bahwa Yerobeam pasti telah mempelajari kelemahan-kelemahan bangsa Israel di dalam hal keseriusan beribadah kepada Allah yang sejati seperti diperintahkan oleh Musa. Itu sebab Yerobeam mencari solusi yang mempermudah bangsa Israel agar tidak perlu pergi ke tempat yang jauh di Yerusalem untuk beribadah di rumah TUHAN. Selain itu penulis sepakat dengan apa yang dikatakan Hill dan Walton bahwa pembaruan keagamaan yang diadakan Yerobeam dapat mengatasi kekuatiran Yerobeam. Yerobeam berharap dapat mencegah orang Ibrani pergi tiga kali dalam setahun ke Bait Allah di Yerusalem yang berada di kekuasaan kerajaan selatan, karena kepergian mereka bisa mempengaruhi iman mereka untuk kembali kepada Allah yang sejati. $^{8}$

Ritual penyembahan dan pengorbanan baru yang diciptakan oleh raja Yerobeam ternyata disambut baik oleh orang Israel di Kerajaan Utara, sehingga mereka pergi menyembah patung lembu emas yang dibuat Yerobeam di dua kota yang telah ditentukan yaitu di Dan, di bagian utara dan yang lainnya di Betel dibagian paling selatan dari Kerajaan Utara. Baik kota Dan maupun Betel memiliki sejarahnya sendiri sebagai kota-kota untuk pusat ritual penyembahan dan pengorbanan. ${ }^{9}$ Maka raja Yerobeam telah berhasil menghidupkan kembali apa yang

\footnotetext{
6 Andrew E. Hill dan John H. Walton, Survey Perjanjian Lama (Malang: Gandum Mas, 1998), 341. Lihat juga https://www.britannica.com/topic/Osiris-Egyptian-god (diakses tanggal 12 Juli 2018). Osiris merupakan dewa kesuburan dan perwujudan raja yang mati dan bangkit di Mesir.

7 Lihat tafsiran John Gill di http://biblehub.com/commentaries/gill/1_kings/12.htm (diakses tanggal 9 Juli 2018).

8 Hill dan Walton, Survey Perjanjian Lama, 341.

$9 \quad$ Bdk Kel. 32; Hak. 18:29-30; Am. 7:13.
} 
dilakukan Harun saat Musa berada di atas gunung Sinai, yaitu membuat kembali patung-patung anak lembu emas dan mengatakan "Hai Israel, inilah Allah-mu, yang telah menuntun engkau keluar dari tanah Mesir!" 10 Yerobeam juga melaksanakan suatu peraturan baru dalam ibadahnya itu, dan tidak sesuai dengan apa yang tertulis dalam hukum taurat. Beberapa di antara peraturan yang dibuatnya itu adalah: Pertama, penetapan hari raya kelima belas di bulan yang ke delapan untuk menandingi perayaan hari ke lima belas di bulan yang ke tujuh di kota Yehuda, Yerusalem. ${ }^{11}$ Kedua, mengangkat imam-imam dari kalangan rakyat biasa yang bukan dari keturunan bani Lewi. ${ }^{12}$ Ketiga, Yerobeam sendiri bertindak selaku imam dalam upacara mempersembahkan korban, dengan demikian Yerobeam berusaha memberikan identitas diri sebagai seorang yang saleh dan taat kepada Allah di mata orang-orang Israel di Kerajaan Utara. ${ }^{13}$

\section{Signifikansi Peran Nabi}

Zaman sekarang istilah "nabi" dan "nubuatan" mengandung beragam pengertian. Seorang peramal dari cuaca, berita/ peristiwa, suatu pertandingan, dan berbagai prediksi peristiwa yang akan terjadi di masa depan bisa merupakan pekerjaan seorang "nabi/ prophet/ pelihat." Kekeliruan linguistik ini merupakan kendala dalam pemahaman yang benar tentang peran nabi di Israel dengan peran pokoknya yang sungguh penting itu. ${ }^{14}$

Istilah "prophet" dalam Bahasa Inggris diambil dari terjemahan Perjanjian Lama dalam Bahasa Yunani yang disebut Septuaginta (LXX).

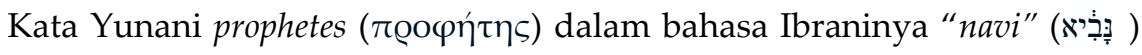
artinya "orang yang dipanggil"15 adalah gabungan dari dua kata, yaitu

\footnotetext{
Kel. 32:4.

Lihat Im. 23:39.

Bdk Bil. 3:3 dengan Bil. 3:10.

1 Raj.12:32-33.

14 Bernhard W. Anderson, Understanding The Old Testament (New Jersey: Prentice-Hall, 1998), 223.

15 Willem A. VanGemeren, Interpreting The Prophetic Word (Grand Rapids: Zondervan,
} 
"pro" ( "phetes" ( "mengucapkan/ memberitakan" sesuatu yang sama sekali bukan ramalan. Seorang nabi juga sering disebut dengan istilah e'ved (עָקָָ) atau hamba. Istilah ini mengindikasikan sikap tunduk dan kerendahan hati. Para nabi adalah para hamba yang resmi yang berbicara untuk mewakili sang Raja Agung. ${ }^{16}$ Pengabaian akan para nabi merupakan dosa yang serius sehingga Daniel mengatakan “...kami tidak taat kepada hambahamba-Mu, para nabi, yang telah berbicara atas nama-Mu (Daniel 9:6). Terkait dengan pembahasan dalam tulisan ini, istilah nabi juga disebut sebagai “ish Elohim” (אָיש אֶלהים), seorang “abdi Allah” sebuah peran yang sakral karena mereka dipilih dan diutus oleh Allah. ${ }^{17}$

Seorang nabi di dalam perjanjian lama, memiliki fungsi ganda, yang pertama sebagai "king makers" dan kedua sebagai "king breakers". 18 Dalam situasi yang seperti ini, Tuhan mengutus seorang abdi Allah dari Yehuda ke Betel untuk menegur raja Yerobeam yang sedang memimpin upacara persembahan korban di atas mezbah.

Beberapa penafsir memberikan sebutan yang berbeda antara "abdi Allah" (אֶיש אֶלהִים), 19 seorang nabi berasal dari Yehuda, dengan "seorang

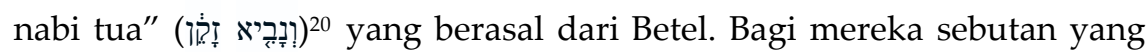
berbeda itu menunjuk kepada pembedaan istilah yang saat itu sudah dipakai di kerajaan Utara dan Kerajaan Selatan. ${ }^{21}$ Josephus mengatakan bahwa nama abdi Allah itu adalah Yadon, dan nama nabi tua itu adalah Mika. ${ }^{22}$ Namun Joseph Blenkinsopp mengatakan bahwa abdi Allah yang

\footnotetext{
1990), 42. Seorang nabi adalah seorang juru bicara bagi Allah dengan panggilan yang jelas sebagai ambasador/ utusan Allah.

16 Thirdmill.org, Ia Memberikan Para Nabi Kepada Kita, Pelajaran Dua: Pekerjaan Seorang Nabi, 3. (diakses tanggal 25 Januari 2018).

17 Ibid., 5.

18 Russell H. Dilday, The Communicators Commentary Series, Old Testament, Vol 9:1, 2 Kings (Texas: Word Books,1987), 167.

19 Lihat 1 Raj. 13:1.

20 Lihat 1 Raj. 13:11.

21 Gwilym H.Jones, 1 and 2 Kings, vol. 1, NCBC (Grand Rapids, 1984), 263.

22 John Gill, 1 Kings 13:1, 11, John Gill"s Exposition of the Entire Bible in www.

Freegrace.net. (diakses tanggal 25 Januari 2018).
} 
berasal dari Yehuda itu adalah anonim dan lokasi pelayanannya tidak tetap. ${ }^{23}$ Willem A. VanGemeren berpendapat bahwa yang jauh lebih signifikan dari pada siapa nama dan apa isi nubuatan seorang nabi adalah sebuah afirmasi, apakah perkataan Allah yang disampaikannya itu benar-benar terjadi. ${ }^{24}$ Untuk menilai apakah abdi Allah dari Yehuda dalam narasi 1 Raja-raja 13 adalah seorang nabi/abdi Allah yang sejati VanGemeren menjelaskan tujuh hal bagaimana membedakan antara seorang nabi sejati dengan nabi palsu. ${ }^{25}$ Pertama, nabi palsu mensinkretiskan antara pewahyuan dan agama, dengan maksud meningkatkan kepopuleran sang nabi. Sedangkan nabi sejati hanya membawa pewahyuan Allah. Kedua, nabi palsu memilih tema-tema dari pewahyuan Allah yang akan menyenangkan umat Allah, dan tidak menyatakan peringatan dan ancaman hukuman Allah. Nabi sejati menyampaikan seluruh maksud Allah kepada umat demi menegakkan kebebasan sejati dari Allah. Ketiga, nabi palsu memupuk ilusi-ilusi dengan membela kepentingan politik yang ada dengan menawarkan solusi masalah secara jangka pendek saja, baik di bidang sosial, politik atau ekonomi. Sedangkan seorang nabi sejati, tetap menjaga independensi-nya dari struktur sosial yang ada. Dan tidak jarang seorang nabi Tuhan adalah pribadi yang kesepian yang tingkah lakunya, pakaian, serta ucapannya menandai identitasnya yang berbeda dengan keadaan pada zamannya. Keempat, nabi palsu hidup dan bekerja untuk kehendak/ kepentingan, visi, atau institusi manusia. Nabi sejati berperan sebagai mediator antara Allah dan manusia. Kelima, nabi palsu sebagai penjaga status quo, berbeda dengan nabi sejati yang meyakini bahwa Allah adalah Raja yang akan mendirikan kerajaan-Nya. Keenam, nabi palsu mengajarkan moralitas yang berpusat pada manusia. Moralitas nabi sejati berpusatkan Allah dan eskatologis. Sebuah etika yang teosentris yang diperlengkapi dengan sistim penafsiran akan hukum

\footnotetext{
23 Joseph Blenkinsopp, A History of Prophesy in Israel (Philadelphia: Westminster Press, 1983), 40.

24 VanGemeren, Interpreting The Prophetic Word, 47.

25 Ibid., 63-65.
} 
Allah dan siapa Allah itu. Dengan demikian setiap tindakannya adalah demi kasihnya kepada Allah bukan bagi sebuah penghargaan dan pengakuan manusia. Ketujuh, nabi palsu memperoleh kepopuleran dan kuasa melalui berbagai program yang sinkretis, tetapi nabi sejati justru menderita, dan menantikan firman Allah digenapi. Selama penderitaannya, nabi sejati itu menantikan tindakan pemulihan melalui berita yang disampaikannya. ${ }^{26}$

Henry menjelaskan relasi antara nabi palsu dengan nabi sejati, "karena nabi-nabi palsu selalu merupakan musuh terbesar bagi nabi-nabi sejati, yang biasanya bertujuan menghancurkan mereka...merusakkan moral mereka dan menarik mereka dari kewajibannya." 27

Jika penulis memperhatikan apa yang Alkitab katakan maka jelaslah bahwa perbedaan fundamental antara seorang nabi palsu dengan nabi sejati ada pada sumber berita yang disampaikannya. Sumber berita yang disampaikan seorang nabi palsu berasal dari rekaan hatinya sendiri sementara nabi sejati berasal dari Allah. ${ }^{28}$

Tidak banyak catatan tentang asal usul abdi Allah itu, namun yang pasti Tuhan mengutusnya untuk menyampaikan suatu nubuatan firman Tuhan tentang mezbah dan tentang keturunan Daud, yaitu Yosia yang akan menyembelih imam-imam bukit pengorbanan dan tentang tulangtulang manusia yang akan dibakar di atas mezbah itu. Mengenai nabi tua

26 Ibid. Van Gemeren membandingkan antara nabi sejati dan palsu dengan table ringkasan berikut:

Nabi Sejati:

Nabi Palsu:

1. Dasar: Pewahyuan

Pewahyuan dan agama

2. Proklamasi yang holistik

Proklamasi yang selektif

3. Lepas dari struktur kekuasaan: politik realitas

Bergantung pada struktur

kekuasaan

4. Anggota dari institusi ilahi dan social

Anggota dari sebuah institusi sosial

5. Visi dari realitas akan kerajaan Allah

Penjaga dari status quo

6. Etika yang Teosentris

7. Menderita bagi Allah

Etika yang berpusatkan manusia

Popularitas dan kuasa

27 Matthew Henry, The Bethany Paralel Commentary (Minneapolis: Bethany House, 1985), 656.

28 Lihat uraian perihal nabi palsu dalam Yer 23:16; Yeh 13: 2,7 dan nabi sejati dalam Kel 4:16; Ul 18:18; Yer 1:9; 2 Ptr 1:21. 
itu, walaupun Henry tidak bisa dengan tegas mengatakan, namun menyebutnya sebagai nabi palsu dengan alasan:

Kemungkinan ia dilatih di antara anak-anak para nabi, dalam sekolah nabi Samuel yang terletak tidak jauh dari tempat tinggalnya, di mana ia tetap mempertahankan nama sebagai seorang nabi, namun bertumbuh dalam keduniawiannya dan bukan kesalehan, roh nubuat telah meninggalkannya. Jika ia telah menjadi seorang nabi yang baik, ia seharusnya telah menegor Yerobeam dengan penyembahan berhalanya itu. ${ }^{29}$

Adam Clarke pun tidak menyebutnya sebagai nabi palsu, ia berpendapat mungkin nabi tua itu dulunya adalah seorang nabi Tuhan yang setia, namun kini telah berubah setia dengan mengikuti Yerobeam dalam penyembahan berhala:

Seorang nabi tua. Mungkin dahulu merupakan nabi Tuhan, yang telah menyimpang dari kesetiaannya, namun tidak jatuh terlalu dalam, sehingga nabi tua itu belum sampai kehilangan pengetahuan akan Allah yang sejati, dan ia pun tidak turut serta dengan Yerobeam dalam penyembahan berhala-berhalanya itu. ${ }^{30}$

Sementara itu, John Gill lebih netral dalam pendapatnya mengenai nabi tua itu. Gill berpendapat, sulit untuk mengatakan bahwa "nabi tua itu adalah seorang yang baik atau jahat." 31 Selanjutnya Gill menguraikan, bila dikatakan ia seorang nabi yang baik, mengapa TUHAN tidak memakainya untuk menegor raja Yerobeam yang ada di dalam wilayah pelayanannya, dan mengapa ia membiarkan raja Yerobeam melakukan penyembahan berhala di Betel, dan juga mengapa anak-anaknya ikut di dalam upacara penyembahan dan pengorbanan yang diperbuat oleh Yerobeam. Bila dikatakan ia seorang nabi yang jahat, maka akan ada kesulitan untuk menjelaskan mengapa ia mempercayai firman yang dikatakan abdi Allah itu dan menguburkan

\footnotetext{
29 Matthew Henry, The Bethany Parallel Commentary, 656.

30 Ibid. Lihat komentar Adam Clarke.

31 Lihat komentar John Gill 1 Raja 13:11 di https://www.biblestudytools.com/

commentaries/gills-exposition-of-the-bible/1-kings-13-11.html. (diakses tanggal 18 Juli 2018).
} 
abdi Allah itu di kuburannya sendiri, serta memerintahkan anakanaknya untuk menguburkannya di sisi abdi Allah itu. Yang jelas nabi tua itu tinggal di Betel, namun sesungguhnya ia berasal dari Samaria. ${ }^{32}$

\section{Perihal Dusta menurut Etika Kristen}

Di dalam etika Kristen dikenal istilah Conflicting Obligation, ${ }^{33}$ yang seringkali menimbulkan dilema saat seseorang hendak menentukan keputusannya. Sebagai contoh saat seorang pemilik rumah yang menyembunyikan seseorang yang hendak dibunuh musuhnya saat Perang Dunia II. Saat menjawab pertanyaan musuh yang menanyakan apakah penghuni rumah tersebut menyembunyikan seseorang, penghuni rumah dapat "berdusta" dengan mengatakan "tidak". J. Douma mengatakan bahwa ketidak jujuran tersebut bukan karena lalai melakukan perintah kesembilan dalam dekalog (Sepuluh Perintah Allah), 34 melainkan demi mencegah mereka yang bersembunyi itu menjadi korban dari musuhnya. Untuk lebih jelasnya Douma mengatakan "untuk menyelamatkan seorang tetangga, mungkin perlu berkata yang tidak sebenarnya (berbohong/berdusta) demi kepentingan kasih. Kami menyebut dusta seperti itu sebuah mendacium officiosum ${ }^{35}$, sebuah dusta (mendacium) yang digunakan dalam sebuah pemenuhan pelayanan kepada orang lain (oficium)." 36 Walter C. Kaizer. Jr. berpendapat lebih tegas dengan mengatakan,

yang disebut bohong karena tugas, menghilangkan betapa bernilainya kebenaran itu dalam pandangan Allah. Bahkan kebohongan untuk tujuantujuan yang sangat baik tidak bebas dari kecaman Allah...Sangat

\footnotetext{
32 Ibid. Bdk. dengan penggenapan nubuatan-nya dalam 2 Raj. 23:15-18.

33 Bdk. J. Douma, Responsible Conduct, trans. Nelson D. Kloosterman (Phillipsburg: P\&R, 2003), 175-181. Conflicting Obligation adalah suatu konflik yang bisa timbul saat pengambilan keputusan etis. Bukan Allah yang menimbulkan konflik ini, melainkan manusia sendirilah yang menyebabkannya.

34 Kel. 20:16 "Jangan mengucapkan saksi dusta tentang sesamamu".

35 Lihat John Calvin, Commentaries on The Book of Joshua (Grand Rapids: Baker, 1993), 47. Pada catatan kaki, mendacium officiosum dari Bahasa Latin yang berarti "suatu dusta yang merupakan sebuah tindakan yang wajib untuk dikatakan."

36 J. Douma, Responsible Conduct, 180.
} 
mungkin untuk mempertahankan suatu posisi yang mutlak tak ada konfliknya. Allah akan menyediakan cara untuk menghindari konflikkonflik tersebut (I Kor 10:13). ${ }^{37}$

Penulis sependapat dengan apa yang dikatakan John Calvin ketika mengomentari tindakan Rahab yang menyembunyikan para pengintai di rumahnya. Rahab terpaksa berdusta demi menyelamatkan nyawa para pengintai itu. 38 Saat seseorang berdusta, sekalipun "dusta wajib/ mendacium officiosum", namun seperti yang dikatakan Calvin "di hadapan Allah yang benar, perbuatan itu tidak lepas dari kesalahan, dan tidaklah murni tanpa noda." 39 Dengan demikian, berkata jujur dan menghindari dusta harus menjadi suatu prioritas di hadapan Allah yang kudus dan berdaulat atas hidup ini. Dusta bisa saja diizinkan Allah dalam kasuskasus tertentu, namun tetap bukan merupakan kehendak-Nya. ${ }^{40}$

\section{Memahami Peran Kedua Nabi Itu}

Abdi Allah ini datang dari Yehuda adalah atas perintah TUHAN (

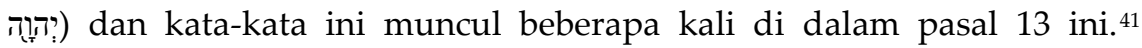
Hendak memberikan konfirmasi bahwa kedatangan abdi Allah tersebut adalah atas otoritas Tuhan. ${ }^{42}$ Dengan beberapa tindakannya, abdi Allah itu menyatakan ketaatannya atas perintah TUHAN yang diterimanya, yaitu dengan: pertama, ia pergi meninggalkan wilayah kekuasaan

\footnotetext{
37 Walter C. Kaizer, Jr., Ucapan Yang Sulit Dalam Perjanjian Lama (Malang: Literatur SAAT, 2007), 104, 106.

38 Lihat Calvin, The Book of Joshua, 47. Dalam kitab Yos. 2:4, Calvin mengatakan bahwa "Secara keseluruhan, itu adalah kehendak Allah agar para pengintai itu bisa selamat, namun Allah tidak setuju cara menyelamatkan mereka melalui/ dengan sebuah kesalahan/ dusta."

39 Calvin, The Book of Joshua, 47.

40 Perhatikan uraian dalam Kaizer, Ucapan Yang Sulit Dalam Perjanjian, 105. "Paling banyak, Allah mengizinkan tujuan-Nya digenapi dengan cara yang paling tidak wajar ini, sebab kasih karunia-Nya bisa bekerja sekalipun ada gerakan-gerakan berencana dari manusia yang berdosa... Memperdebatkan masalah bohong seperti ini, bukan hanya merupakan penggalian arti dan teologi yang lemah melainkan juga teodisi (sistem teologi natural yang berusaha membuktikan kebenaran ilahi dalam mengizinkan keberadaan yang jahat) yang lebih buruk."

$41 \quad$ Lihat 1 Raj. 13: 1, 2, 5, 9, 17.

42 Jamieson, Fausset, Brown, The Bethany Paralel Commentary, 654.
} 
Kerajaan Selatan (di Yehuda, raja Rehabeam) lalu pergi ke Betel ke wilayah kekuasaan Kerajaan Utara (di Betel, raja Yerobeam); kedua, menyerukan firman TUHAN atas mezbah yang dipakai Yerobeam mempersembahkan korban, sehingga pecah dan menunjukkan penyertaan TUHAN atas dirinya; ketiga, menolak ajakan raja Yerobeam untuk makan, minum dan kembali melalui jalan yang telah dilaluinya, bahkan menolak suatu hadiah yang akan diberikan raja Yerobeam kepadanya, bukan karena ia takut, namun semata-mata mau menunjukkan ketaatannya akan perintah TUHAN yang diterimanya; keempat, diperkirakan 326 tahun kemudian, apa yang dinubuatkan oleh abdi Allah itu tergenapi di dalam 2 Raja-raja 23:15-16.43 Dari empat poin di atas, terbukti bahwa sebelum abdi Allah itu berjumpa dengan nabi tua yang di Betel itu, ia adalah seorang yang taat akan perintah TUHAN, dan TUHAN pun meneguhkannya dengan tanda-tanda ajaib dan keberanian menghadapi raja Yerobeam.

Persoalan baru muncul ketika nabi tua yang tinggal di Betel itu berbohong dengan mengatakan bahwa ia pun mendapatkan "perintah

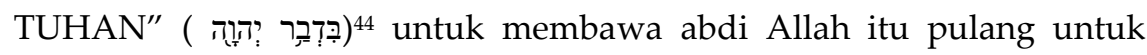
makan bersama dengannya. Oleh sebab itu, dapat dipahami mengapa abdi Allah itu bersedia untuk mengikuti nabi tua itu.

Perihal mengenai nabi tua itu, tidak banyak keterangan mengenai dirinya, kecuali ia sudah tua dan berasal dari Samaria (2 Raja-raja 23:18). ${ }^{45}$ Sebagai seorang nabi, tugasnya adalah menyampaikan firman Tuhan. Di dalam perikop ini, tidak dijelaskan mengapa nabi tua itu tidak mendapatkan perintah Tuhan untuk menegur dan bernubuat kepada raja

\footnotetext{
43 Jamieson, Fausset, Brown, The Bethany Parallel Commentary, 732. Dijelaskan di sini bahwa peristiwa ini merupakan suatu penggenapan nubuatan yang luar biasa, yang dicatat dalam Alkitab. Nama Yosia keturunan Daud sudah dinubuatkan dan namanya juga disebutkan 326 tahun sebelum ia lahir.

$44 \quad 1$ Raj. 13:18.

45 Tidak ada ketentuan mengenai sampai usia berapa seorang nabi masih bisa tetap melayani. Yang pernah ada tertulis di dalam kitab Taurat, adalah batas usia seorang imam untuk bertugas sampai usia lima puluh tahun (Bil. 8:25). Namun di dalam Perjanjian Baru kita membaca tentang usia imam Zakaria yang masih melayani melebihi umur lima puluh tahun (Luk. 1:7).
} 
Yerobeam, yang sebenarnya ada dalam wilayah pelayanannya di Betel. Matthew Henry lebih suka mengatakan bahwa nabi tua itu adalah seorang nabi palsu, karena menurutnya sudah seharusnyalah nabi tua itu menegur kesalahan yang dilakukan raja Yerobeam, dan bukan justru membohongi abdi Allah yang dari Yehuda itu. ${ }^{46}$ Yang pasti, karena dusta nabi tua itu, abdi Allah tersebut harus mati dengan cara mengenaskan yaitu diterkam singa di dalam perjalanannya kembali dari Betel.

Setelah kematian abdi Allah itu, nabi tua tadi menunjukkan kebaikannya dengan mengambil mayat abdi Allah itu, meratapinya dan menguburkannya di kuburannya sendiri. Bahkan nabi tua sendiri berpesan kepada anak-anaknya agar menguburkannya di kuburan yang sama dengan abdi Allah itu jika suatu hari kelak ia mati. Di sini kita melihat, bahwa nabi tua itu tidak memandang abdi Allah itu sebagai musuhnya, atau memandangnya secara negatif, melainkan sebagai sesama nabi, yang "seprofesi" dengannya. Nabi tua itu pun meyakini akan nubuatan dari abdi Allah itu tentang keturunan Daud, yakni Yosia yang suatu hari akan menggenapi nubuatan abdi Allah itu. ${ }^{47}$

\section{Mengenai Dusta dan Nubuat Nabi Tua}

Ada beberapa pendapat para ahli mencermati dusta nabi tua yang mengakibatkan abdi Allah itu dihukum TUHAN. Simon J. DeVries mengatakan bahwa abdi Allah itu seharusnya memperhatikan seluruh tingkah lakunya, termasuk urusan yang mungkin dianggapnya hal-hal kecil/ "trivial" yaitu makan, minum, dan kembali melalui jalan yang sama seperti saat ia datang. Perbuatan ajaib yang menunjukkan kuasa rohani yang menyertai abdi Allah itu, telah nyata ketika ia berdoa kepada TUHAN untuk memulihkan tangan Yerobeam yang kejang itu. Namun hal itu tidak berarti bahwa abdi Allah itu boleh tidak taat akan

\footnotetext{
46 Henry, The Bethany Parallel Commentary, 656.

$47 \quad 1$ Raj. 13:32, dan penggenapannya tertulis di dalam 2 Raj. 23:15-16.
} 
urusan yang dipandangnya sebagai "hal-hal kecil". ${ }^{8}$ Russell H. Dilday agak berbeda dengan J. DeVries. Dilday melihat keseriusan terhadap sebuah panggilan pelayanan. Panggilan Allah dalam pelayanan kenabian dari abdi Allah itu, mungkin melebihi panggilan Yerobeam menjadi seorang raja. Keseriusan panggilan kenabian harus dijaga bukan hanya waspada terhadap godaan yang besar namun juga yang "tak kentara/subtle". Dilday mengatakan mungkin tampak tidak adil, jika membandingkan antara Yerobeam yang penuh ketidaktaatan namun tetap dibiarkan hidup, sementara abdi Allah itu harus mati hanya karena sebuah ketidaktaatannya mengikuti perkataan dusta dari nabi tua yang mengajaknya makan, dan minum. ${ }^{49}$ Berbeda dengan kedua ahli di atas, R. D. Patterson dan Herman J. Austell melihat dari sisi karakter abdi Allah itu. Ketidaktaatan abdi Allah itu, untuk mau makan dan minum bersama nabi tua tersebut, membuktikan kelemahan mendasar dari karakternya: ia memandang pelaksanaan terhadap perintah Allah jelas merupakan instruksi/ "command" ketimbang sebagai sebuah keyakinan/"conviction". ${ }^{50}$

Dari uraian ketiga pandangan para ahli di atas, penulis berpendapat bahwa secara logika, ada beberapa kemungkinan yang membuat abdi Allah itu memenuhi undangan nabi tua itu untuk makan dan minum bersama. Pertama, karena nabi tua itu mengatas namakan "perintah TUHAN". Kedua, karena hendak menghormati orang yang lebih tua dan sesama nabi. Terakhir, karena keadaan fisiknya yang letih dan memang dalam kondisi lapar yang mendorongnya untuk makan dan minum di rumah nabi tua itu. Namun, lebih jauh penulis berpendapat, ada satu hal terpenting perlu dicatat bahwa dusta bukanlah menjadi sebuah penyataan Allah, dan bukan pula cara Allah untuk bertindak. "Allah bukanlah manusia, sehingga Ia berdusta bukan anak manusia, sehingga Ia menyesal..." (Bilangan 23:19a). Ketika TUHAN mengutus

\footnotetext{
48 Simon J. DeVries, Word Biblical Commentary I Kings (Texas: Word Books, 1985), 174.

49 Dilday, The Communicator's Commentary, 168.

50 R.D. Patterson \& J. Hermann Austel, The Expositor's Bible Commentary 1, 2 Kings (Grand Rapids: Zondervan, 1988), 119.
} 
nabi Yeremia untuk menubuatkan tentang pembuangan bangsa Israel ke Babel, nabi Yeremia pun menghadapi dusta dari nabi Hananya, yang nyata-nyata tidak diutus TUHAN (Yeremia 28:1-17). Demikian pula ketika nabi Mikha bin Yimla harus berhadapan dengan nabi Zedekia dan empat ratus nabi Israel, di mana Zedekia dan semua nabi israel telah dimasuki roh dusta atas seijin TUHAN, dengan maksud mendatangkan celaka atas raja Ahab sesuai dengan nubuatan dari nabi Mikha (1 Rajaraja 22:22).

Pemakaian kata "Firman TUHAN" ( sesungguhnya firman yang berasal dari TUHAN sendiri. Donald J. Wiseman menegaskan bahwa "Perkataan Tuhan datang. Hal ini membedakan antara nubuatan yang sejati dengan yang palsu, yang timbul dari imajinasi." ${ }^{51}$ Menyikapi nubuatan palsu ini, TUHAN telah berfirman melalui nabi Yeremia, bahwa nabi palsu hanya mengungkapkan penglihatan rekaan hatinya sendiri saja, dan bukan apa yang datang dari mulut TUHAN. ${ }^{52} \mathrm{Di}$ sini terlihat jelas, bahwa walaupun sebelumnya nabi tua itu telah berdusta dengan menyampaikan pesan yang bukan firman TUHAN (1 Raja-raja 13:18), namun pesan/ berita/ nubuatan yang diucapkan kemudian dari nabi tua itu (1 Raja-raja 13:20) adalah benar-benar berasal dari TUHAN sendiri dan bukan merupakan hasil rekaan si nabi tua itu.

Nubuatan yang diucapkan oleh nabi tua itu kepada abdi Allah, mengandung dua hal yang penting untuk diperhatikan: Pertama, abdi Allah itu telah "memberontak," tidak menaati perintah TUHAN. Di sini letak kegagalan dari abdi Allah itu, ia menjadi bimbang antara mengutamakan firman yang diterimanya dari TUHAN dengan mendengar perkataan orang lain, yang adalah "seprofesi" dengannya. Semestinya firman TUHAN harus mendapat tempat tertinggi dibanding suara dari luar, termasuk dari seorang nabi tua itu. Kedua, akibat dosa

\footnotetext{
51 Donald J. Wiseman, $1 \& 2$ Kings an introduction and commentary (Downers Grove: InterVarsity Press, 1993), 147.

52 Yer. 23: 16.
} 
pemberontakannya maka TUHAN menghukum abdi Allah itu. Hukuman yang diterimanya adalah mayatnya tidak dikubur dalam kuburan keluarga, bahkan tercampak di jalan, karena terkaman seekor singa. Meninggal dengan mayat yang tidak dikubur adalah suatu bentuk kutukan dan dikuburkan pada tempat yang jauh dari kuburan keluarga dan di antara orang-orang atau bangsa asing adalah suatu bentuk aib bagi orang itu. ${ }^{53}$

Dalam perikop ini, terlihat bahwa ketaatan kepada Allah tidak bisa digantikan dengan apapun. Kesuksesan abdi Allah itu, dalam melaksanakan apa yang Tuhan perintahkan untuk disampaikan kepada raja Yerobeam, tidak boleh menggantikan unsur ketaatan kepada Allah secara keseluruhan. Karena ketidaktaatan akan perintah TUHAN jugalah, maka TUHAN telah menolak raja Saul sebagai raja atas Israel (1 Samuel 15:23). Seringkali kesuksesan sebuah pelayanan pun, bisa membuat seseorang terlena dan tidak waspada terhadap sebuah ketaatan. Kita juga dapat memperhatikan firman yang datang kepada nabi Yehezkiel atas janji pembaharuan bangsa Israel, bahwa TUHAN akan memberikan hati yang taat (Yehezkiel 11:19).

Peristiwa yang menimpa abdi Allah akibat ketidaktaatannya juga merupakan kejadian yang aneh. Firman yang telah diucapkan oleh nabi tua itu benar-benar terjadi, di mana abdi Allah itu diterkam singa dalam perjalanan pulang, dan mayatnya tidak diapa-apakan, bahkan singa dan keledai itu berdiri di samping abdi Allah yang telah mati itu. Semua ini terjadi pasti karena ada campur tangan TUHAN yang telah berfirman. Di sini kita perhatikan, bahwa di satu sisi, TUHAN berfirman kepada nabi tua itu, dan apa yang difirmankanNya melalui nabi tua itu, benar-benar terjadi, namun disisi lain nabi tua itu berdusta kepada abdi Allah itu.

\footnotetext{
53 Wiseman, 147.

Contoh lain: Yakub ketika ia mau meninggal, meminta Yusuf untuk menguburkannya di kuburan nenek moyangnya yaitu di gua Makhpela di tanah Kanaan, dan bukan di Mesir (Kej. 47:29-30), demikian pula dengan Barzilai orang Gilead itu, yang hendak mati dekat dengan kubur ayah dan ibunya, di kotanya sendiri (2 Sam. 19:37).
} 
Suatu dusta yang telah menyebabkan abdi Allah itu mati dengan cara yang mengenaskan.

\section{Dipakai oleh Allah}

Dalam hal ini terdapat suatu kontras, bagaimana mungkin melalui mulut yang sama, telah diucapkan suatu dusta, yang adalah merupakan suatu dosa (Mazmur 5:7), dengan firman TUHAN yang kudus, yang merupakan nubuatan. Hal ini dapat dipahami atau dilihat sebagai berikut: Pertama, TUHAN berhak atas apapun untuk dipakai bagi penggenapan rencanaNya, karena Dia adalah TUHAN yang berdaulat. Termasuk ketika TUHAN mau memakai nabi tua yang berdusta dengan mulutnya itu. Kedua, berdusta tetap merupakan dosa, dan TUHAN tidak pernah bertoleransi dengan dosa. Namun demikian ada alasan kuat yang lain, ketika TUHAN memakai dusta nabi tua itu, yaitu demi menguji ketaatan abdi Allah sebagai utusan-Nya.

Hidup bergaul dengan Allah, serta hidup yang berkenan kepadaNya, pasti menuntut suatu kekudusan hidup, hal ini nyata dalam firmanNya "Kuduslah kamu sebab Aku kudus" (Imamat 11:45). Karena di dalam hidup bergaul, dan berkenan kepada Allah, ada suatu relasi antara orang tersebut dengan Allah. Sementara itu, Allah bisa memakai apa saja dan siapa saja untuk menjadi alat di tanganNya untuk menyatakan kehendak dan karyaNya. Pemazmur menyatakan bahwa Allah memakai dunia ciptaan, untuk memberitakan kemuliaanNya (Mazmur 19:2). TUHAN memakai keledai untuk berbicara dan menegur Bileam (Bilangan 22: 28, 30). TUHAN memakai bangsa Babel untuk menghukum bangsa Israel ke dalam pembuangan. TUHAN memakai Koresy untuk membawa bangsa Israel kembali ke tanahnya. TUHAN memakai Iblis saat menyatakan bahwa Ayub adalah seorang yang saleh, jujur, takut akan Allah dan menjauhi kejahatan (Ayub 1:1). Semua contoh di atas hendak menegaskan bahwa apa dan siapa saja yang dipakai Allah adalah yang "digunakan" Allah demi maksud, tujuan yang Allah tentukan. Jadi kesuksesan sebuah pelayanan bukanlah membicarakan 
perihal berkenan kepada Allah atau tidak, tetapi menyatakan Allah berdaulat dan berkuasa untuk memakai apapun dan siapapun guna mencapai apa yang dikehendakiNya. Dari uraian di atas, maka dapat dipahami ketika Bileam, seorang yang biasa melakukan tenung bisa dipakai untuk memberkati Israel (Bilangan 24:10, 17), dan Kayafas pun bisa dipakai Allah untuk menyampaikan suatu nubuatan tentang Tuhan Yesus (Yohanes 11: 49-51). Demikianlah kita juga dapat memahami perkataan/ kecaman Tuhan Yesus tentang mereka yang disebut sebagai "pembuat kejahatan", walau pun mereka telah bernubuat dan mengusir setan demi nama Tuhan Yesus (Matius 7:21-23).

\section{Implikasi Pemakaian Dusta}

Bila kita memperhatikan beberapa kasus dusta yang tercatat di dalam Alkitab, maka untuk waktu sesaat, tampaknya orang yang berdusta itu telah berhasil memperoleh apa yang diinginkannya. Beberapa di antaranya Yakub yang mendustai Ishak, memperoleh berkat hak kesulungan (Kejadian 27:11, 12, 28), dan raja Ahab yang memperoleh kebun anggur Nabot karena mengajukan saksi dusta (1 Raja-raja 21), Gehazi yang berdusta kepada Naaman untuk memperoleh hadiah (2 Raja-raja 5:20-27), Mahkamah agama yang mengajukan saksi dusta untuk memvonis mati Tuhan Yesus (Matius 26:59-66), dan sebagainya. Dari semua perbuatan dusta yang dilakukan, para penulis Alkitab justru memandang dusta mereka sebagai "kesalahan" mereka, dan bukan sebagai "keberhasilan/ kesuksesan" dari yang melakukannya. Dan dalam beberapa kasus, akibat langsung dari dusta mereka, langsung mendapatkan ganjaran dengan hukuman yang setimpal. Sebagai contoh: Yakub harus berpisah dengan keluarganya, dan Ahab harus dihukum mati dan Gehazi harus kena penyakit kusta Naaman. Maka dalam hal dosa berdusta, Allah tidak pernah berkompromi, dan hal ini dipertegas dengan firman yang tertulis di dalam hukum taurat:" ...janganlah kamu berbohong, dan janganlah kamu berdusta seorang kepada sesamanya." (Imamat 19:11). Kini semakin jelas, bahwa adalah tidak mungkin 
TUHAN mencegah manusia untuk berdusta tetapi Allah bisa memakai dusta. Apa yang dilakukan nabi tua itu dengan dustanya adalah jelas bukan keinginan TUHAN, dan juga bukan merupakan perintah-Nya.

Demikian pula perihal nabi tua yang berdusta itu, yang telah dipakai Allah untuk menghukum abdi Allah yang tidak taat akan perintah TUHAN, bukan berarti nabi tua itu adalah seorang yang berkenan kepada Allah, namun sebatas hanya dipakai Allah, untuk menghukum abdi Allah yang tidak taat dan memberontak itu. Demikian juga yang dialami oleh raja Yerobeam, yang walaupun telah mendapatkan peringatan dan teguran keras melalui pelayanan abdi Allah itu, namun tetap tidak mau bertobat, akhirnya dilenyapkan dan dipunahkan dari muka bumi (1 Raja-raja 13: 34). Narasi dalam 1 Raja-raja 13 ini mengingatkan kita bahwa seorang nabi Allah pun tidak otomatis berkenan kepada Allah, bisa saja ia hanya dipakai Allah, namun orang yang berkenan dihati-Nya tentu dipakai untuk mewujudkan kehendakNya.

\section{Kesimpulan}

Melalui uraian yang telah berikan, penulis berpendapat bahwa nabi tua dalam narasi 1 Raja-raja 13 ini adalah bukan seorang nabi sejati. Jika ia seorang nabi sejati, maka sudah seharusnya ia menjalankan fungsinya sebagai seorang nabi, yaitu menyampaikan kebenaran sekalipun harus menanggung resiko apapun. Sangat mungkin, berbagai situasi kondisi yang terjadi di sekitarnya, telah mempengaruhi integritasnya sebagai seorang nabi sejati.

Jauh lebih penting dari penilaian penulis terhadap sang nabi tua dan abdi Allah itu maka akhirnya dapat diambil beberapa aplikasi praktis yaitu: Pertama, dusta bisa dilakukan oleh siapa saja termasuk orang yang mengaku sebagai seorang "hamba Tuhan" namun pada kenyataannya adalah seorang nabi palsu. Sebab itu, perlu waspada dan menguji setiap perkataan seperti peringatan rasul Yohanes dalam surat 1 Yohanes 4:1. Kedua, Tuhan yang berdaulat atas hidup manusia dapat 
memakai apa dan siapa saja untuk melaksanakan segala kehendak-Nya. Alat yang dipakai itu, tidak harus suatu yang kudus, atau memiliki persyaratan khusus. Ketiga, Tuhan pasti menggenapi setiap janji atau nubuat yang berasal dari pada-Nya, namun orang yang tidak taat, walaupun telah dipakai untuk menyampaikan janji atau nubuat itu tidak luput dari hukuman Tuhan. Keempat, ketika pelayanan seorang hamba TUHAN terlihat sepertinya berhasil dan tampaknya orang itu dipakai Allah untuk melakukan pekerjaan dan rencana-Nya, belum tentu hamba TUHAN itu berkenan di hadapan Allah dan memiliki hubungan/ hidup bergaul dengan Allah. Kelima, ketaatan kepada Allah adalah diatas segalanya, termasuk terhadap kesuksesan ataupun ancaman sebuah pelayanan. Hal ini tentunya mengingatkan kita pada sikap rasul Petrus ketika diancam agar tidak memberitakan nama Tuhan Yesus seperti ditulis di kitab Para Rasul, "Tetapi Petrus dan Yohanes menjawab mereka: 'Silakan kamu putuskan sendiri manakah yang benar dihadapan Allah: taat kepada kamu atau taat kepada Allah'” (Kisah Rasul 4:19). Keenam, para pelayan Tuhan juga diingatkan agar tidak memberontak terhadap perintah dan firman Allah yang telah terimanya. Ketika seseorang merasa bahwa ia sedang dipakai Allah dengan luar biasa, haruslah tetap rendah hati untuk mawas diri, apakah hidupnya juga sudah berkenan kepadaNya, atau hanya sekedar "dipakai" saja. Sehingga akhirnya seorang pelayan Tuhan bisa menjadi seperti apa yang rasul Paulus katakan tentang Daud, yang hidup "melakukan kehendak Allah pada zamannya, lalu ia mangkat dan dibaringkan di samping nenek moyangnya, ..." (Kisah Rasul 13:36). 